\title{
Sistem Pengiriman Data Suhu Dan Gambar Berbasis IoT
}

\author{
Nadia Pertiwi ${ }^{1}$, Ahmad Riyad Firdaus ${ }^{1 *}$ \\ ${ }^{1}$ Politeknik Negeri Batam, Jurusan Teknik Elektro, Batam \\ *E-mail: rifi@polibatam.ac.id
}

\begin{abstract}
Abstrak
Pengiriman data suhu dan gambar merupakan faktor penting dalam suatu proses kerja alat yang sedang beroperasi. Salah satu metode pengirimannya adalah dengan sistem online. Pada pengiriman data suhu dan gambar perlu diperhatikan juga kebutuhan software maupun hardware sehingga bisa dilakukan pengontrolan secara otomatis untuk mencegah terjadinya ketinggalan informasi. Sebelum dilakukannya pengontrolan, perlu diketahui karakteristik suhu lingkungan dan camera yang digunakan pada area alat tersebut. Oleh karena itu, pengujian ini bertujuan merancang sistem pengiriman data suhu dan gambar secara otomatis. Untuk mendapatkan hasil data dan gambar yang sesuai, alat tersebut menggunakan sensor suhu DS18B20 dan Modul Camera Raspberry Pi berbasis Internet Of Thing (IoT). Data sensor dan hasil gambar diolah menggunakan Raspberry Pi Model B kemudian dikirim melalui e-mail melalui jaringan internet dan realtime database sehingga dapat diakses dimanapaun dan kapanpun. Pengujian ini dilakukan dengan melakukan kalibrasi dan validasi pembacaan sensor suhu DS18B20 pada saat pengambilan data suhu. Hasil pengujian sensor selisih pembacaan suhu antara sensor dengan termometer sebesar 0,6. Hasil pengujian menunjukan bahwa data sensor dan gambar dapat terkirim secara realtime pada e-mail menggunakan jaringan internet dengan delay rata-rata sebesar 2 detik.
\end{abstract}

Kata Kunci: Sensor Suhu DS18B20, Modul Camera Raspberry Pi, Raspberry Pi

\begin{abstract}
Temperature and image data transmission is an important factor in the work process of an operating device. One method of shipping is by an online system. In sending temperature and image data, it is also necessary to pay attention to software and hardware requirements so that control can be done automatically to prevent information lag. Before controlling, it is necessary to know the characteristics of the ambient temperature and the camera used in the area of the tool. Therefore, this test aims to design a system for sending temperature data and images automatically. To get the appropriate data and image results, the device uses a DS18B20 temperature sensor and an Internet-based Of Thing (IoT) Raspberry Pi Camera Module. Sensor data and image results are processed using Raspberry Pi Model B and then sent via e-mail through the internet and realtime databases so that they can be accessed anywhere and anytime. This test is carried out by performing calibration and validation of the DS18B20 temperature sensor reading when taking temperature data. The results of testing the sensor temperature difference between the sensor with a thermometer of 0.6. The test results show that sensor data and images can be sent in realtime to e-mails using an internet network with an average delay of 2 seconds.
\end{abstract}

Keywords: DS18B20 Temperature Sensor, Raspberry Pi Camera Module, Raspberry Pi 


\section{Pendahuluan}

Mesin produksi adalah perangkat yang sangat penting bagi industri manufaktur karena terkait kelangsungan bisnis sebuah perusahaan manufaktur. Kegagalan atau kerusakan mesin produksi akan sangat berpengaruh terhadap proses produksi jika tidak ditangani langsung. Terkadang, tidak setiap menit teknisi bisa mengawasi semua mesin agar berjalan dengan baik. Kerusakan akibat overheat dari sebuah mesin produksi bisa saja terjadi ketika teknisi tidak ada di tempat, sehingga perlu ada teknologi yang dapat mengawasi kondisi permesinan dan memberikan informasi secara otomatis jika terjadi kerusakan terhadap permesinan tersebut.

Internet of Things (loT) adalah suatu teknologi yang memanfaatkan konektifitas internet secara berkesinambungan dalam memperluas pemanfaatannya. Teknologi ini menggabungkan benda fisik dan virtual melalui data capture, misal dengan menggunakan sensor serta akses kontrol jarak jauh.

Perangkat loT yang sering digunakan dalam pembuatan sistem adalah Raspberry Pi, perangkat ini biasanya digunakan sebagai akses atau juga bisa sebagai penghubung antara internet dengan sensor sehingga data dari sensor tersebut dapat diakses melalui internet. Dengan prinsip kerja IoT yang dapat dibuat dengan memadukan sensor suhu DS18B20, Modul Camera Raspberry Pi, Raspberry Pi serta e-mail yang akan digunakan.

\section{Metode Penelitian}

Berdasarkan flowchart sistem, proses kerja dari perancangan alat dirancangan ini diawali dengan pendektesian menggunakan sensor suhu DS18B20 dan pendektesian menggunakan camera. Sensor suhu ini akan mendeteksi suhu panas untuk menghasilkan data dan untuk camera ini akan mendeteksi adanya pergerakan pada objek yang digunakan. Jika sudah terdeteksi maka akan melanjutkan proses selanjutnya. Sensor sudah dalam keadaan menyala akan otomatis mendeteksi data dari suhu panas yang terbaca dan mengaktifkan camera untuk melakukan pengambilan gambar.
Setelah diketahui adanya data masuk dari suhu panas yang dideteksi dan camera mendeteksi adanya pergerakan pada objek, maka Raspberry pi akan saling berkomunikasi dengan program phyton. Melalui program phyton mampu membuat database untuk melakukan proses pengambilan data suhu panas serta pemngambilan gambar pada objek. Hasil pengambilan data dan gambar telah terintegrasi oleh VNC Viewer sebagai media perangkat lunaknya sehingga dapat menyimpan data dan gambar dalam bentuk file.

Untuk proses pengiriman data dan gambar agar bisa dilihat, membutuhkan Application Programming Interface digunakan sebagai perangkat lunak untuk membuat aplikasi dalam bentuk login. Login ini berguna sebagai tempat untuk grafik data, dan e-mail sebagai tempat untuk pengiriman data yang terbaca dan gambar yang terbaca, disini bisa dilihat hasil dari yang didapatkan dalam pendeteksian.

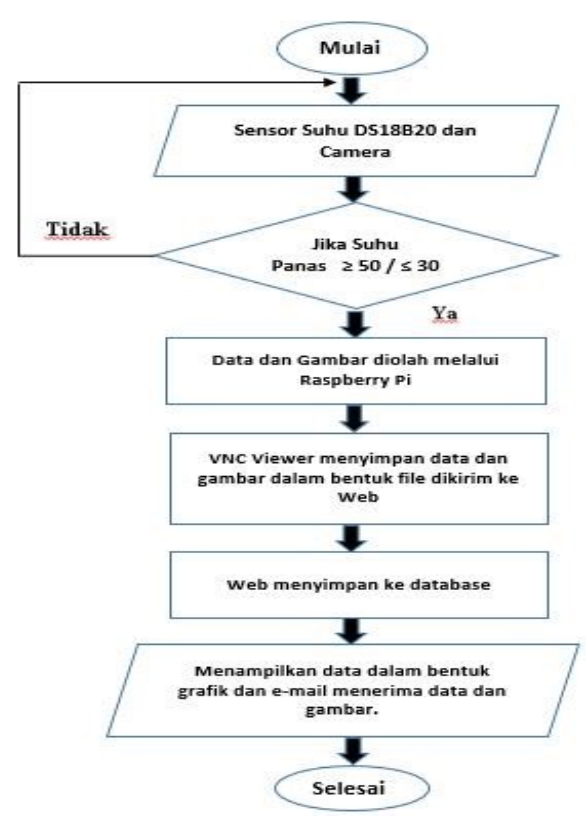

Gambar 1. Flowchart Sistem Kerja/Diagram alir kerja

Diagram blok berfungsi sebagai acuan dalam memahami alur kerja alat tersebut. Selain itu diagram blok berfungsi untuk mengetahui bagianbagian sistem dari suatu alat. Dalam merancang 
sebuah sistem, diperlukan gambaran sebuah alur kerja secara keseluruhan, berikut blok diagram sistem pada alat yang dirancang ini bisa dilihat pada Gambar 2.

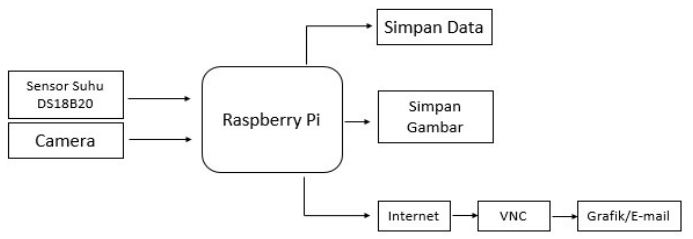

Gambar 2. Rangkaian Blok Diagram

\section{Hasil dan Diskusi}

Hasil pengujian pengukuran Suhu Sensor DS18B20 menggunakan pembandingan Digital Infrared Termometer hasilnya pada Table 1 dan Gambar 3.

Tabel 1. Hasil Pengujian Suhu Panas Sensor DS18B20 Dengan Digital Infrared Thermometer

\begin{tabular}{|c|c|c|c|}
\hline $\begin{array}{l}\text { Pengukuran } \\
\text { Suhu Dengan } \\
\text { Digital Infrared } \\
\text { Thermometer } \\
\left({ }^{\circ} \mathrm{C}\right)\end{array}$ & $\begin{array}{l}\text { Pengukuran } \\
\text { Sensor } \\
\text { Suhu } \\
\text { DS18B20 } \\
\left({ }^{\circ} \mathrm{C}\right)\end{array}$ & Error & $\begin{array}{l}\text { Error } \\
(\%)\end{array}$ \\
\hline 34,6 & 35,4 & 0,8 & 2,2 \\
\hline 37,3 & 38,3 & 0,8 & 2,0 \\
\hline 39,7 & 39,8 & 0,1 & 0,2 \\
\hline 40,9 & 42,5 & 1,6 & 3,7 \\
\hline 42,8 & 43,0 & 0,2 & 0,4 \\
\hline 43,7 & 44,1 & 0,4 & 0,9 \\
\hline 44,9 & 45,2 & 0,3 & 0,6 \\
\hline 47,0 & 48,3 & 1,3 & 2,6 \\
\hline 50,9 & 51,2 & 0,3 & 0,5 \\
\hline 54,3 & 55,1 & 0,8 & 1,4 \\
\hline
\end{tabular}



Gambar 3. Grafik Hasil Pengujian Suhu Panas Sensor DS18B20 Dengan Digital Infrared Thermometer

Selanjutnya dilakukan pengujian tegangan sensor suhu DS18B20. Pengujian ini bertujuan untuk mengetahui tegangan pada sensor. Pen- gujian dilakukan dengan cara mengukur tegangan sensor ketika terjadi perubahan suhu. Pengukuran tegangan sensor menggunakan alat ukut multimeter. Hasil pengukuran tegangan sensor bisa dilihat pada Tabel 2 .

Tabel 2. Hasil Pengujian Tegangan Sensor

\begin{tabular}{cc}
\hline Suhu & $\begin{array}{c}\text { Output Tegangan } \\
\text { (V) }\end{array}$ \\
\hline 35,4 & 1,3 \\
38,1 & 1,7 \\
39,8 & 1,9 \\
42,5 & 2,1 \\
43,0 & 2,1 \\
44,1 & 2,2 \\
45,2 & 2,24 \\
48,3 & 2,29 \\
51,2 & 2,32 \\
55,1 & 2,34 \\
\hline
\end{tabular}

Berdasarkan Tabel 2. dapat dilihat bahwa pengukuran dilakukan pada saat perubahan nilai suhu, maka akan didapat tegangan pada sensor tetap. Sehingga dikatakan sensor bekerja secara stabil. Berikut grafik hasil data pengujian tegangan sensor DS18B20 bisa dilihat pada Gambar 4.

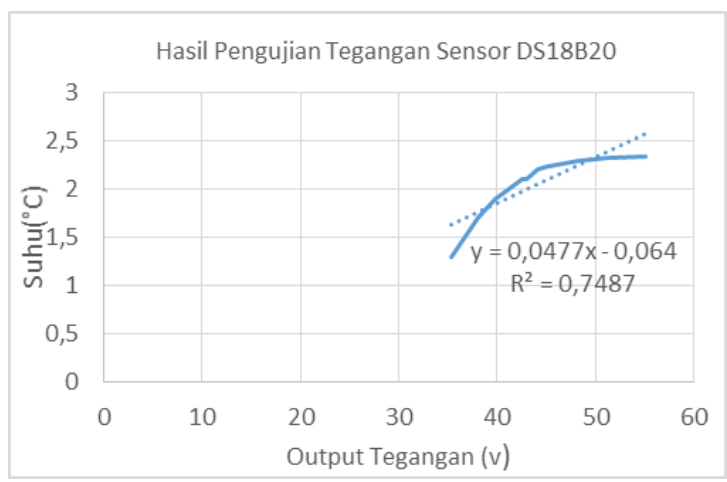

Gambar 4. Grafik Hasil Pengujian Tegangan Sensor DS18B20

Pada grafik diatas memiliki persamaan linear sebagai berikut:

$$
y=0,0477 x-0,064
$$

Dimana $x$ adalah nilai tegangan keluaran sensor dan y adalah data suhunya $\left({ }^{\circ} \mathrm{C}\right)$. Sensor ini memiliki rentang linear dari suhu $30^{\circ} \mathrm{C}-50^{\circ} \mathrm{C}$, jika suhu terdeteksi diatas $50^{\circ} \mathrm{C}$ sensor tidak bisa membaca nilai dengan baik.

Dari data-data tersebut diperoleh persamaan linear dimana $\mathrm{x}$ adalah nilai tegangan keluaran 
sensor dan y adalah data suhunya $\left({ }^{\circ} \mathrm{C}\right)$ yang diperoleh dari hasil pengujian menggunakan multimeter digital.

Berikut hasil notifikasi data dan gambar yang terbaca pada e-mail hasilnya pada Tabel 3.

Tabel 3. Hasil Data Dan Gambar Pada E-mail No. Waktu Hasil Tampilan pada e-mail Keterangan

1 07.12

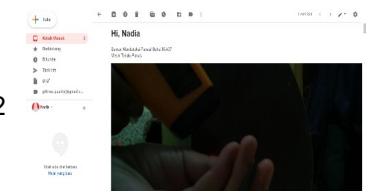

Mendeteksi

Panas! 35,437

Mesin Terlalu Panas

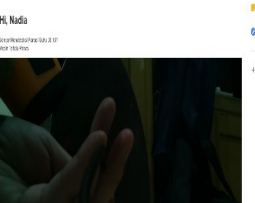

Sensor Mendeteksi

Panas! 38,187

Mesin Terlalu Panas

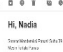

$3 \quad 07.57$

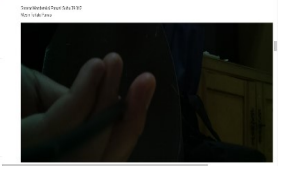

Sensor Mendeteksi

Panas! 39,812

Mesin Terlalu Panas

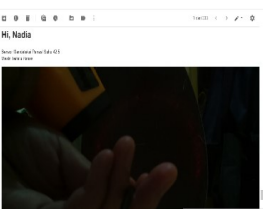

Sensor Mendeteksi Panas! 42,5

Mesin Terlalu Panas



Sensor Mendeteksi

Panas! 43,0

Mesin Terlalu Panas



Sensor Mendeteksi

Panas! 44,125

Mesin Terlalu Panas

$6 \quad 08.48$

Sensor Mendeteksi

Panas! 45,25

Mesin Terlalu Panas

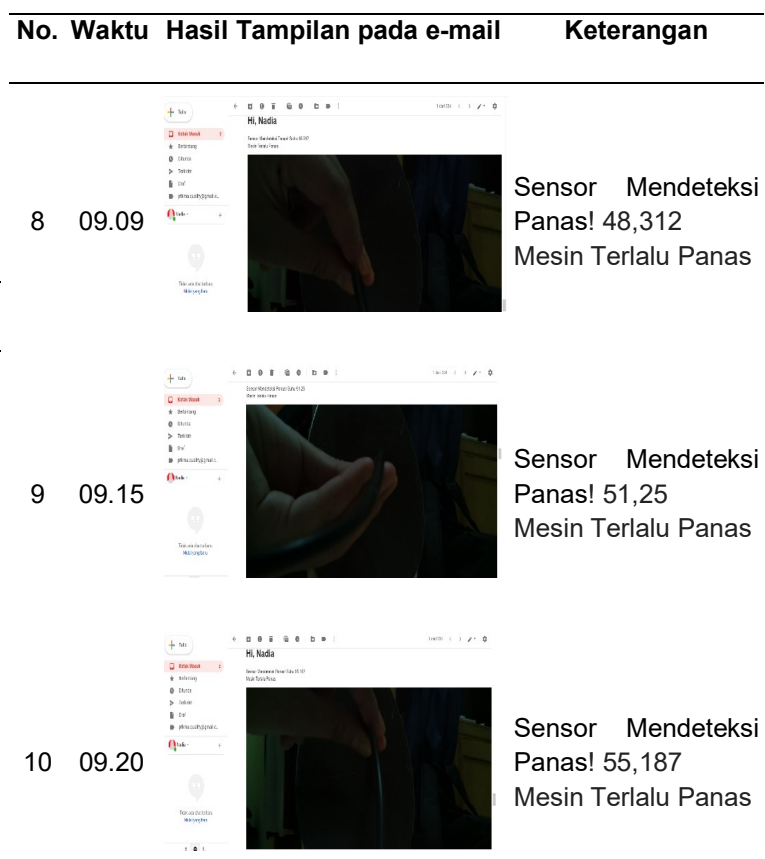

Sensor suhu DS18B20 digunakan untuk mendeteksi suhu elemen pemanas pada setrika telah berfungsi dengan baik, terbukti dari hasil pengujian pada sensor suhu DS18B20 didapatkan tingkat rata-rata error sebesar, yang berarti tingkat akurasi pengukuran sensor ketika dibandingkan dengan Digital Infrared Thermometer tidak terlalu jauh. Sensor suhu DS18B20 memiliki akurasi yang baik. Pada Proses pengambilan data menggunakan grafik, hasil pengujian tersebut tetap berjalan sesuai data yang diukur menggunakan sensor suhu DS18B20. Pengujian sensor suhu DS18B20 menggunakan elemen pemanas pada setrika dilakukan secara bertahap karena setrika tersebut memiliki temperature suhu minimum hingga maksimum, sehingga suhu tersebut berubahubah.

\section{Simpulan}

Pengiriman data suhu dan gambar dirancang untuk mempermudah memonitoring keadaan mesin yang sedang bekerja, sehingga ketika terjadi sesuatu, maka admin akan segera mengetahui dan dapat segera melakukan penanganan agar tidak menimbulkan dampak yang signifikan. Sistem pengiriman data suhu dan gambar dibuat dengan Raspberry $\mathrm{Pi}$, sensor suhu DS18B20 dan Modul Camera Raspberry PI sebagai alat pengambilan data suhu dan gambar. 
Perintah untuk pengambilan data suhu dan gambar dibuat dengan mengirimkan data ke database pada Raspberry $P i$ dibuat dengan menggunakan sistem API (Application Programming Interface) dan aplikasi dibuat dengan bahasa pemrograman PHP untuk aplikasi web untuk e-mail. Sebagai tempat penyimpanan data, digunakan database MySQL yang sudah terkoneksi dengan e-mail dan aplikasi web. Data data suhu yang sudah terkumpul, dapat disajikan dalam bentuk grafik pada aplikasi web.

Sistem pengambilan gambar ini mendeteksi objek tertentu, memberikan notifikasi secara langsung kepada penggunanya dengan mengirimkan pemberitahuan ke e-mail secara real time. Tujuan diberikannya camera ini untuk mengambil gambar secara otomatis jika sensor suhu DS18B20 mendeteksi suhu panas. Proses pengambilan gambar pada Modul Camera Raspberry bisa dilihat pada Gambar 5 .

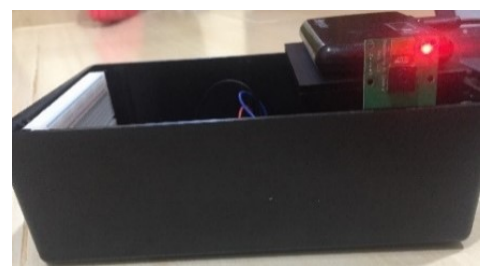

Gambar 5. Proses Camera Untuk Pengambilan Gambar

Spesifikasi dalam pemilihan jenis camera tidak ada, yang terpenting adalah camera dapat melakukan pengambilan gambar tanpa henti agar tidak ada kejadian terlewat saat user melakukan streaming pada proses monitoring. Pada camera ini akan disambungkan ke Raspberry Pi, sedangkan Raspberry Pi sendiri disambungkan ke jaringan lokal yang memiliki akses internet agar dapat mengirimkan gambar pada e-mail.

\section{Ucapan Terima Kasih}

Ucapan terima kasih disampaikan kepada Program Studi D4 Teknik Mekatronika, Jurusan Teknik Elektro, Politeknik Negeri Batam yang telah memberikan dukungan atas terbentuknya jurnal ASEECT ini.

\section{Daftar Pustaka}

[1] Nurazizah, E., Ramdhani, M., Rizal, A., "Rancang Bangun Termometer Digital Berbasis Sensor DS18B20", Universitas Telkom, ISSN:2355-9365 e-Proceeding of Engineering: Vol.4, No.3, Desember, 2017.

[2] T.Budioko "Sistem Monitoring Suhu Jarak Jauh Berbasis Internet Of Things menggunakan Protokol Mqtt," Stmik Akakom, Hal. 353-358, 2016.

[3] Ardeman, Sayed Muchallil, Afdhal."Kinerja Server Basis Data Pada Aplikasi Web Berbasis Raspberry Pi", Universitas Syiah Kuala, e-ISSN: 2252-7036 Vol.2 No.3, 2017.

[4] Periyaldi, Bramanto, A.W.P., Wajiansyah, A.,"Implementasi Sistem Monitoring Suhu Ruang Server Satnetcom Berbasis Internet Of Things (IOT) Menggunakan Protokol Komunikasi Message Queue Telementary (MQTT)", Polteknik Negeri Samarinda, ISSN 2338-6649 Jurnal Teknologi Terpadu Vol. 6 No. 1, April, 2018. 